\title{
Energy Efficiency in Buildings and Excess Summer Mortality in the UK
}

\author{
Ali Mohamed Abdi \\ abdia7@uni.coventry.ac.uk \\ Coventry University, Faculty of Engineering, Environment \& Computing, Coventry, Cv1 2jh, UK \\ Andrew Arewa \\ ab6887@coventry.ac.uk \\ Coventry University, Faculty of Engineering, Environment \& Computing, Coventry, Cv1 2jh, UK \\ Mark Tyrer \\ ac5015@coventry.ac.uk \\ Coventry University, Faculty of Engineering, Environment \& Computing, Coventry, Cv1 2jh, UK \\ Rex Asibuodu Ugulu \\ rexugulu@gmail.com \\ Federal University of Science and Technology (FUTO), School of Environmental Technology, Quantity \\ Surveying Department, Nigeria
}

\begin{abstract}
One of the main objective of the building design is to provide comfort and safety to occupants, particularly during adverse weather conditions. In most part of the world, people stay indoors during adverse weather conditions, thus increasing energy consumption. In UK, vulnerable people such as the elderly are highly affected with mortality rate during extreme weather conditions. The 2003 heatwave reached average of $38.5^{\circ} \mathrm{C}$ in the UK resulting in the death toll of 2,234. The 10 days period of extreme heat is thought to be the warmest about the last 500 years. Across Europe, the 2003 heatwave resulted in 20,000 deaths; in France alone, the number reached 15,000. Similarly, the 2018 summer heatwaves, reached $35.5^{\circ} \mathrm{C}$ contributing to 863 deaths. Yet, there is little research regarding impact of energy efficiency in building and deaths caused by excessive heatwaves in the UK. The study aims to investigate the impact of energy efficiency in buildings and excessive heatwave deaths among elderly people in the UK. Research question asked is; do energy efficiency programmes and policies contribute to excessive summer deaths in the UK? .The study adopted quantitative research method with participants drawn from low/average income households, in west midlands part of UK, between 2003/04 to 2017/18. Initial findings show that there is a significant relationship between energy efficiency adoption, government policies and excessive summer deaths.
\end{abstract}

Keywords: Buildings; Energy efficiency; Excess heatwaves; Thermal comfort

\section{INTRODUCTION}

Majority of people living in cold countries prefer summer weather to winter, however things become uncomfortable when summer temperatures exceed the average normal temperature. The UK has seen some of the hottest summers in recent years with the mean temperature of $17^{\circ} \mathrm{C}$ and maximum temperature of $38^{\circ} \mathrm{C}$. The 2003 and 2018 heatwave led to almost 3000 excess deaths in UK and 80,000 across Europe (ONS, 2019; Taylor et al, 2018; Robine et al, 2008). A Prediction by Met Office states that heatwaves of similar 
calibre will continue in succeeding years up to 2040s. Consequently, there is growing concern over the impact of these heatwaves especially on vulnerable groups such as the elderly and disabled people. Numerous researches conducted after the 2003 heatwaves found that deaths in care homes increased by $42 \%$. Similarly, in Paris, $92 \%$ of deaths reported in 2003 were of the elderly who lived alone (Kovats et al, 2006). Yet, there is scarcity of research regarding extreme heatwaves and excessive summer deaths.

\section{OVERHEATING IN BUILDINGS}

Current building designs and regulations in UK focus more on retaining heat during winter compared to cooling in the summer period (Lomas \& Porritt, 2017). Overheating is notably a major problem in most traditional houses and new houses with poor insulation. The Chartered Institution of Building Service Engineers (CIBSE 2019) defines overheating as "a situation when the local indoor thermal environment presents conditions in excess of those acceptable for human thermal comfort or those that may adversely affect human health". Overheating can have a direct impact on health, safety, comfort and productivity (Taylor et al, 2015). Consequently, the main people affected during extreme summer weather are the elderly people. They are less sensitive to ambient conditions, hence psychologically unable to regulate their body temperature during hot weather leading to morbidity (Astrom et al, 2011). Figure 1 illustrates number of deaths registered in England and Wales.

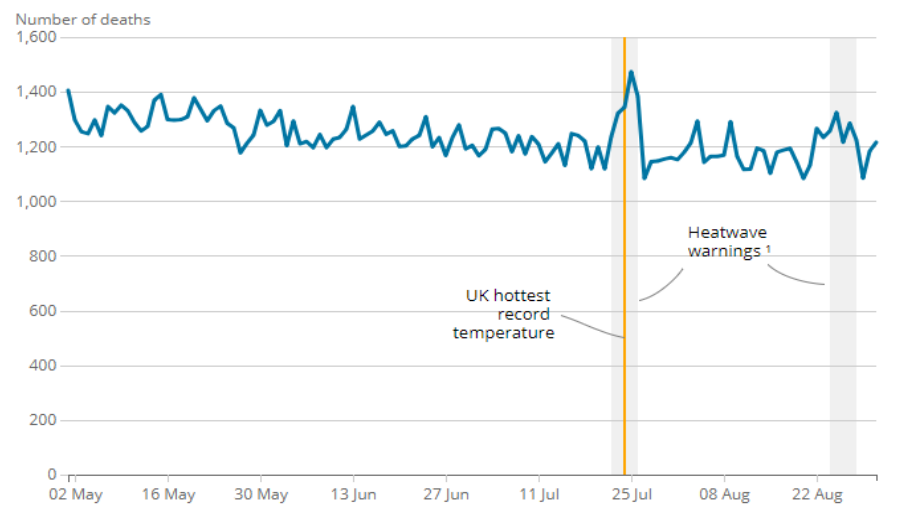

Source: Deaths registered weekly in England and Wales, Office for National Statistics

Figure 1: Summer deaths registered in England and Wales (ONS, 2019).

\subsection{Energy Efficiency Policies in UK}

Having in place a suitable energy efficiency policy across UK buildings is an important aspect especially when it comes to reducing greenhouse gas emissions, tackling fuel poverty, insulations and reducing energy bills. However, UK has a diverse building stock that requires different energy remedies. UK government statistics reveal that $15 \%$ of the existing buildings were built after 1990, meaning that most homes before this period were constructed with none or little information about insulation standards and energy performance (CCC, 2016). In UK, there are various stakeholders responsible for 
safeguarding the public against heatwaves; Public Health England (PHE), Department of Health and Social Care (DHSC), Department of Food and Rural Affairs (DEFRA) and the Met Office (Howarth et al, 2019). The responsibility of preparing and publishing the heatwave plan for England is mainly conducted by PHE. Consequently, with the rising risk of unprecedented heatwave event in the future, the country has limited policies that ensure robust safeguards against overheating and adaptation in buildings (CCC, 2019).

\section{DATA COLLECTION AND ANALYSIS}

Data from the study were collected from the Office of National Statistics (ONS) and Met Office. The ONS data consist of the last five years' summer deaths and the Met office data was sought to determine the average temperature for the period. Months considered for summer temperature are May, June, July and August. Due to limitations, the study data were analysed quantitively using excel and SPSS version 25 . The main statistical methods used are Pearson correlation analysis test and Regression analysis. The correlation test looked at the relationship between temperature and summer deaths in the UK. Thus, this produced a score of $0.74(74 \%)$, meaning that there is significant relationship between high temperature in summer months and mortality. Figure 1 shows the relationship between temperature and deaths. Similarly, figure 3 illustrates last five years' summer deaths in UK. Thus, higher the temperature, the higher the number of deaths.

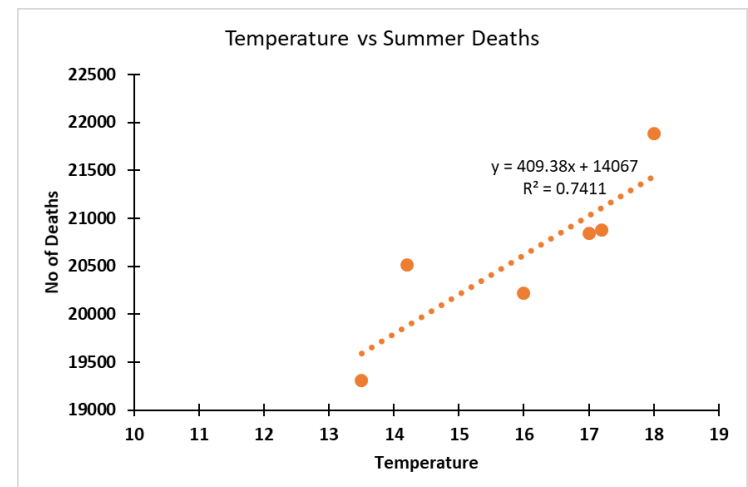

Figure 2: Relationship between Temperature and summer deaths in UK

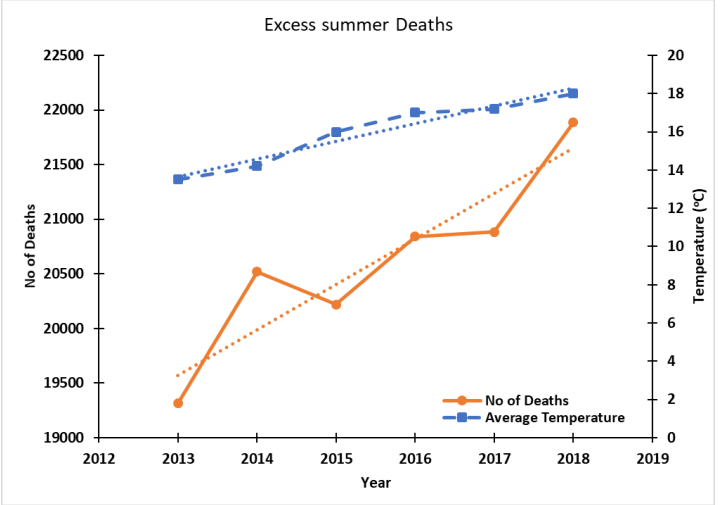

Figure 3: Excess summer deaths for the last five years (ONS, 2019) 


\section{FINDINGS, DISCUSSION AND CONCLUSION}

The study findings and literature reveal that heat related fatalities will continue to increase as temperature rises in the UK particularly during the summer period. Most UK houses have poor insulation and therefore do not retain heat well. Consequently, there are no clear policies or regulations in the UK that aim to raise awareness on the impact of heat related deaths and climate change. Besides, UK building code is not explicit on the use of air-conditioners in residential buildings. Hence, there are fears that installing air-conditioners in residential buildings in the UK will ramp up electricity consumption. Current policies favour winter period where efforts are made to improve energy efficiency of housing stocks and reduction of average heat loss. Similarly, in UK, heat and welfare concerns continue to focus on heat retention rather than summertime comfort. With ever-changing climate and aging population, there is need for alternatives to cooling buildings during summer heatwaves. However, there is little empirical evidence to help identify the best solutions to excess summer heatwaves and deaths. Debates are currently ongoing regarding inventing energy efficient dual heating and cooling systems for buildings in the UK.

\section{REFERENCES}

Heat and Preventable Deaths in the Health and Social care System (2019). [pdf] London: Committee of Climate Change. Available at: https://www.theccc.org.uk/wp-content/uploads/2019/07/ Outcomes-Heat-preventable-deaths-case-study.pdf [Accessed 25 Nov. 2019].

Hughes, C. \& Natarajan, S. (2019). Summer thermal comfort and overheating in the elderly. Building Services Engineering Research and Technology, 40(4), pp. 426-445.

Kovats, R. \& Kristie, L. (2006). Heatwaves and public health in Europe. European Journal of Public Health, 16(6), pp. 592-599.

Lomas, K. \& Porritt, S. (2016). Overheating in buildings: lessons from research. Building Research \& Information, 45(1-2), pp. 1-18.

Ons.gov.uk. (2019). Number of deaths in the summer period - Office for National Statistics. [online] Available at: https://www.ons.gov.uk/peoplepopulationandcommunity/healthandsocialcare/ causesofdeath/datasets/numberofdeathsinthesummerperiod [Accessed 17 Nov. 2019].

Taylor, J., Wilkinson, P., Davies, M., Armstrong, B., Chalabi, Z., Mavrogianni, A., Symonds, P., Oikonomou, E. \& Bohnenstengel, S. (2015). Mapping the effects of urban heat island, housing, and age on excess heat-related mortality in London. Urban Climate, 14, pp. 517-528. 